\title{
Effects of Fabrication Parameters on the Enzyme Loading and Sensor Response of Enzyme-Carrying Conductive Polymer Electrodes
}

\author{
Saipin Thanachasai, Shoichiro Yoshida, and Tadashi Watanabe ${ }^{\dagger}$ \\ Institute of Industrial Science, The University of Tokyo, 4-6-1 Komaba, Meguro, Tokyo 153-8505, Japan
}

\begin{abstract}
Hydrogen peroxide sensors where horseradish peroxidase (HRP) is incorporated into pyrrole/3-alkylsulfonate pyrrole copolymer films deposited on an $\mathrm{SnO}_{2}$ electrode (HRP/Py-PS electrode) were investigated with regard to the effects of the fabrication parameters (electropolymerization charge, deposition current density, and electrodeposition solution $\mathrm{pH}$ ) on the amount of surface-immobilized enzyme and the sensor response. The amount of incorporated enzyme was determined with a method recently developed by ourselves. The results suggest that the amount of entrapped enzyme increases almost linearly with the total charge passed, and strongly depends on the polymer film growth rate and the electropolymerization $\mathrm{pH}$. These findings open up a way to control the amount of enzyme and the resultant response of the biosensor by modifying the preparation conditions.
\end{abstract}

(Received January 22, 2003; Accepted March 3, 2003)

\section{Introduction}

Electropolymerized conducting polymers have attracted much attention as immobilization matrices for fabricating enzyme electrodes since 1986. ${ }^{1,2}$ Among various conducting polymers, polypyrrole and its derivatives are most widely used for entrapping enzymes, because polypyrrole can be easily electrodeposited onto an electrode surface from aqueous solutions, which are compatible with most biological elements. $^{1-13}$

Electrochemical polymerization is a rapid one-step procedure to obtain conducting polymers on an electrode surface by either galvanostatic, potentiostatic or multi-cycling deposition techniques. The thickness of the polymer film can be controlled by the total charge passed during electropolymerization, which offers control over the amount of biological element being immobilized. The amount of enzyme immobilized in the very vicinity of the electrode surface would greatly influence the sensor response, and is therefore an essential parameter in the fabrication of enzyme electrodes. However, due to the lack of a simple and rapid method for determining a minute quantity of immobilized enzyme, few studies have reported on the quantity of enzyme actually present on the electrode surface. ${ }^{7,14-16}$

It is known that the properties of synthesized polymer films are affected by the electropolymerization conditions, as are the quantities of enzyme entrapped in them when used as an immobilization support. If the actual amount of enzyme incorporated into polymer films can be quantified, the influence of the electropolymerization conditions on the immobilized enzyme could be investigated. Further, if the effect of such electropolymerization conditions on the resulting sensor response can be concomitantly evaluated, the relationship between the sensor response and the amount of surface-

† To whom correspondence should be addressed. immobilized enzyme could be established. This would be advantageous for optimizing the fabrication conditions for the biosensor design.

In view of this, we recently devised ${ }^{17}$ a simple and rapid method to determine an enzyme immobilized into electropolymerized polymer films by combining a thin-layer electropolymerization cell with the well-known Bradford protein assay. ${ }^{18}$ The method has been successfully applied to the determination of horseradish peroxidase (HRP) entrapped into poly\{pyrrole-co-[4-(3-pyrrolyl)butanesulfonate]\} (Py-PS) copolymer films. ${ }^{17}$ Such a novel hydrogen peroxide sensor has been developed recently ${ }^{19}$ by adopting a strategy of incorporating anionic fixed charges to polypyrrole so that the positively-charged HRP at the usual electropolymerization solution $\mathrm{pH}$ could be incorporated into this polyanionic film via electrostatic interactions, resulting in a superior sensor performance and stability over the conventional HRP/PPy electrode.

In the present work, the relationship between the sensor response and the amount of surface-immobilized enzyme was investigated by studying the effects of the preparation variables, i.e., the electropolymerization charge, the deposition current density, and the growth solution $\mathrm{pH}$, on the amount of incorporated enzyme and the response of the HRP/Py-PS electrode. The results would provide us with a novel basis for controlling the biosensor performance.

\section{Experimental}

\section{Materials}

Tin oxide (8000 - $10000 \AA$ thick) coated glass plates as a base electrode were obtained from Asahi Glass (Japan). Horseradish peroxidase (HRP, grade II) from Roche Diagnostics and pyrrole (Py) from Kanto Chemicals were used without further purification. Coomassie Plus Protein Assay Reagent was 
obtained from Pierce and used as supplied. 4-(3-Pyrrolyl)butanesulfonic acid sodium salt (hereafter abbreviated as "pyrrole sulfonate, PS") was synthesized following a procedure described in the literature, ${ }^{20}$ and characterized by NMR $\left({ }^{1} \mathrm{H}\right.$ NMR $\left(\mathrm{D}_{2} \mathrm{O}\right): \delta 1.52-1.63(\mathrm{~m}, 4 \mathrm{H}), 2.36(\mathrm{t}, 2 \mathrm{H}), 2.78(\mathrm{t}, 2 \mathrm{H})$, $5.97(\mathrm{~m}, 1 \mathrm{H}), 6.56(\mathrm{br} \mathrm{s}, 1 \mathrm{H}), 6.66(\mathrm{~m}, 1 \mathrm{H}))$. Diluted hydrogen peroxide standard solutions were freshly prepared from a $31 \%$ hydrogen peroxide aqueous solution prior to use. All other reagents were of analytical grade or the best grade available.

\section{Determination of enzyme incorporated into electropolymerized} polymer films

The amount of HRP immobilized in the HRP/Py-PS electrode was determined using a procedure described elsewhere. ${ }^{17}$ A thin-layer electropolymerization cell was constructed with a tin oxide working electrode, a platinum-black counter electrode and a silicone rubber spacer. An $\mathrm{SnO}_{2}$-coated glass plate $(2.0 \mathrm{~cm} \times$ $2.5 \mathrm{~cm}$ ) was pretreated with hot sulfuric acid diluted with water (1:1) for about $30 \mathrm{~min}$; its effective area was $1.0 \mathrm{~cm} \times 2.0 \mathrm{~cm}$ after electropolymerization cell assembly. The counter electrode was a platinum plate $(2.0 \mathrm{~cm} \times 2.5 \mathrm{~cm})$ with the platinum-black area of $1.0 \mathrm{~cm} \times 2.0 \mathrm{~cm}$. A 2-mm-thick silicone rubber spacer was placed between the $\mathrm{SnO}_{2}$-coated glass electrode and the platinum black electrode to provide an inner volume of a $400-\mu \mathrm{L}$ electropolymerization solution. The thinlayer cell was filled with an aqueous solution $(400 \mu \mathrm{L})$ containing $0.04 \mathrm{M}$ pyrrole (Py), 0.01 M PS, and $0.6 \mathrm{~g} \mathrm{~L}^{-1} \mathrm{HRP}$. Electrochemical polymerization was performed galvanostatically to keep a constant polymerization rate during electrolysis.

The enzyme concentration was assayed by monitoring the increased absorbance at $595 \mathrm{~nm}$ due to the binding of protein to Coomassie Brilliant Blue (CBB) G-250. The HRP concentration in an aqueous stock solution $\left(2 \mathrm{mg} \mathrm{mL}^{-1}\right)$ was determined spectrophotometrically at $403 \mathrm{~nm}$ using an extinction coefficient $(\varepsilon)$ of $102 \mathrm{mM}^{-1} \mathrm{~cm}^{-1} .^{21}$ A set of HRP standards $\left(1-30 \mu \mathrm{g} \mathrm{mL} \mathrm{m}^{-1}\right)$ was then prepared by properly diluting the stock solution with $1 / 15 \mathrm{M}$ phosphate buffer ( $\mathrm{pH}$ 6.4). To each $2 \mathrm{~mL}$ of enzyme solution, $2 \mathrm{~mL}$ of the CBB G-250 solution was added and after 2 min from mixing the absorbance at $595 \mathrm{~nm}$ was measured versus a water reference. The absorbance at $595 \mathrm{~nm}$ for each standard was subtracted by the $595 \mathrm{~nm}$ reading for a blank prepared from $2 \mathrm{~mL}$ of $1 / 15 \mathrm{M}$ phosphate buffer and $2 \mathrm{~mL}$ of the CBB solution. A calibration curve for HRP, being linear up to $30 \mu \mathrm{g} \mathrm{mL}-1$, was thus obtained.

The quantity of HRP entrapped into the electropolymerized film was determined from the difference of the enzyme concentration in a monomer solution before and after electropolymerization. The monomer solution was diluted 20fold with 1/15 M phosphate buffer ( $\mathrm{pH}$ 6.4) before a measurement to fit to a calibration curve. In all of the experiments the HRP-containing monomer solutions before and after electropolymerization were assayed in triplicate, and an average value of absorbance at $595 \mathrm{~nm}$ was adopted to calculate the amount of enzyme.

Fabrication of enzyme electrodes and measurement of sensor performance

An $\mathrm{SnO}_{2}$-coated glass plate $(1.0 \mathrm{~cm} \times 1.0 \mathrm{~cm})$ was pretreated and used as a working electrode. HRP/Py-PS electrodes were fabricated by galvanostatic electropolymerization in a $6-\mathrm{mL}$ aqueous solution containing $\mathrm{Py}, \mathrm{PS}$, and $\mathrm{HRP}$. $\mathrm{Ag} / \mathrm{AgCl}$ and a platinum black wire were used as reference and counter electrodes, respectively.

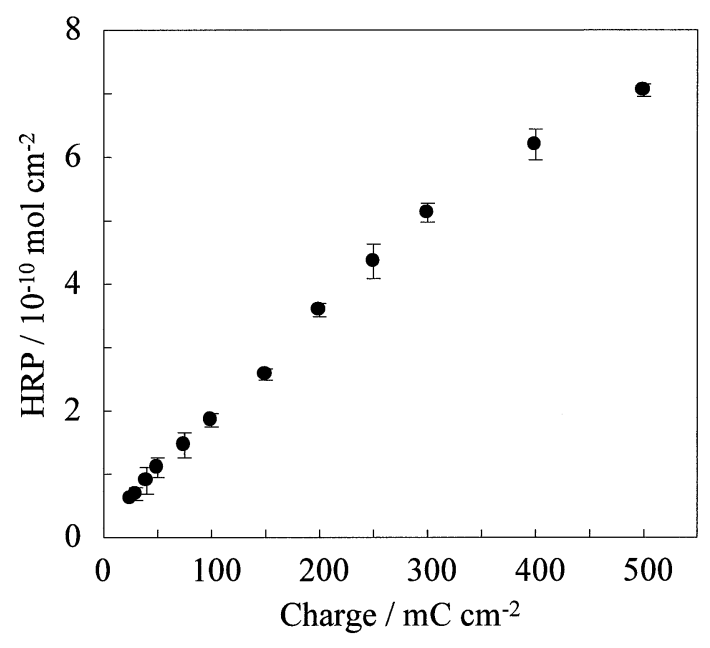

Fig. 1 Amount of HRP immobilized in HRP/Py-PS electrodes as a function of the total charge passed during electropolymerization.

The amperometric response to hydrogen peroxide was evaluated in a $1 / 15 \mathrm{M}$ phosphate-buffered solution $(\mathrm{pH}$ 6.4) at $30^{\circ} \mathrm{C}$. Reference and counter electrodes were $\mathrm{Ag} / \mathrm{AgCl} / \mathrm{KCl}$ (saturated) and platinum black wire, respectively. The enzyme electrodes were polarized at $+150 \mathrm{mV}$ vs. $\mathrm{Ag} / \mathrm{AgCl}$ and the output current was recorded in a quiescent solution. Calibration plots were obtained by the stepwise injection of $\mathrm{H}_{2} \mathrm{O}_{2}$ standard solutions.

\section{Results and Discussion}

\section{Effect of the film thickness}

The amperometric response of an enzyme electrode depends on several factors: the amount of enzyme immobilized in the polymer film, mass transport of the substrates, and the kinetics of the enzyme reaction.

In the first place, we investigated the effect of the electropolymerization charge on the amount of immobilized enzyme and sensor response of HRP/Py-PS electrodes. The amount of HRP incorporated into the Py-PS copolymer prepared with a deposition charge in the range of $25-500 \mathrm{mC}$ $\mathrm{cm}^{-2}$ was determined. To ensure a common copolymer matrix property, the electropolymerization was done at a constant current density of $0.1 \mathrm{~mA} \mathrm{~cm}{ }^{-2}$, and the total charge was varied. The result given in Fig. 1 clearly shows that the amount of entrapped HRP increased almost linearly with the total charge passed, up to at least $300 \mathrm{mC} \mathrm{cm}^{-2}$. A similar result has been reported for polypyrrole films with entrapped glucose oxidase and hydroquinone sulfonate. ${ }^{7}$ This finding suggests that both the polymer film and enzyme distribution are uniform when prepared by galvanostatic electropolymerization.

The sensor response was measured at a mild potential of +150 $\mathrm{mV}$ vs. $\mathrm{Ag} / \mathrm{AgCl}$. Figure 2 shows the calibration curves for HRP/Py-PS electrodes prepared with a series of electropolymerization charges. The inset depicts the cathodic current response toward $10^{-4} \mathrm{M} \mathrm{H}_{2} \mathrm{O}_{2}$ plotted as a function of the total charge. With an increase in the electropolymerization charge, the cathodic current response increased and reached a peak at $50 \mathrm{mC} \mathrm{cm}^{-2}$, and decreased thereafter.

In the lowest range of the electropolymerization charge (0.5 $5 \mathrm{mC} \mathrm{cm}^{-2}$ ), the current response changes drastically with the charge passed, as can be seen in the inset of Fig. 2. This implies 


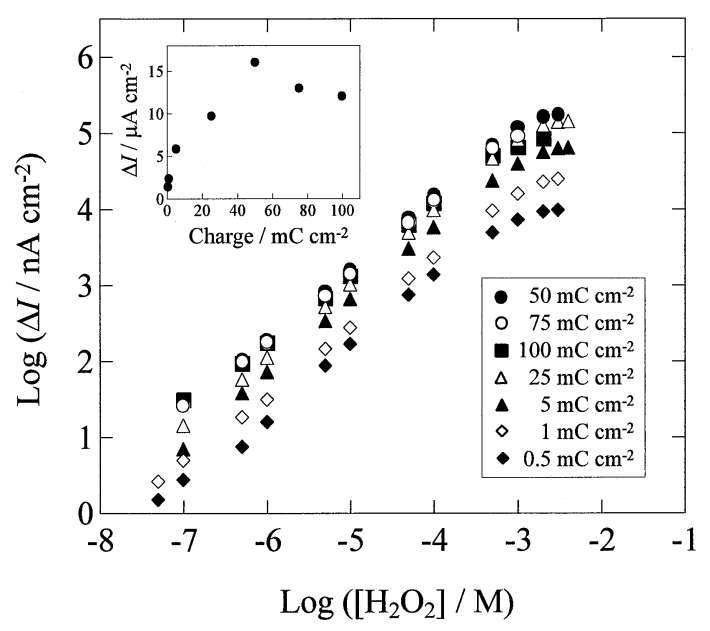

Fig. 2 Calibration curves for HRP/Py-PS electrodes prepared with electropolymerization charges $0.5(\diamond), 1(\diamond), 5(\Delta), 25(\Delta), 50(\bullet)$, $75(\mathrm{O})$, and $100(\mathbb{}) \mathrm{mC} \mathrm{cm}^{-2}$. The inset shows the cathodic current response to $10^{-4} \mathrm{M} \mathrm{H}_{2} \mathrm{O}_{2}$ against the electropolymerization charge.

that in this range the amount of incorporated HRP is not proportional to the electropolymerization charge. This may be attributed to the formation of films thicker than the theoretical values.

The film thickness $(d)$ can be formulated as follows: ${ }^{22}$

$$
d=\frac{M Q}{n F A \rho}
$$

where $M$ is the molar mass of a repeating unit, $n$ the number of electrons associated with polymer formation ( 2 here), $F$ Faraday's constant, $\rho$ the estimated density of the film, $A$ the electrode surface area, and $Q$ the charge associated with the polymer formation.

Gros et al. ${ }^{23}$ demonstrated via ellipsometry that Eq. (1) is valid for polypyrrole films thicker than a few tenths of nanometers, but that the films formed with a smaller charge (e.g., $0.03 \mathrm{mC} \mathrm{cm}^{-2}$ ) are much thicker than the theoretical value. They ascribed this to a chemical polymerization of pyrrole occurring during the electropolymerization, or to continued growth of the polymer after the electrochemistry has been completed.

With increasing the deposition charge up to $50 \mathrm{mC} \mathrm{cm}^{-2}$, the sensor response increased, resulting most probably from an increase in the quantity of enzyme entrapped in the polymer films. This indicates that in this range the current response depends on the amount of enzyme immobilized and thereby is controlled by the enzymatic reaction kinetics.

However, as the deposition charge exceeded $50 \mathrm{mC} \mathrm{cm}^{-2}$, a decrease in the current response was observed, despite a continued increase in the amount of immobilized enzyme. The sensor output here seems to no longer be controlled by the amount of immobilized enzyme, but by the diffusion rate of hydrogen peroxide in the thicker films.

\section{Effect of the deposition current density}

The influence of the deposition current density on the amount of enzyme entrapped in the HRP/Py-PS electrodes was evaluated with fixed electropolymerization charges of 50, 150, and $300 \mathrm{mC} \mathrm{cm}^{-2}$. The current density was varied at each deposition charge between 0.01 and $0.5 \mathrm{~mA} \mathrm{~cm}{ }^{-2}$. Figure 3 illustrates that the highest amount of immobilized HRP was

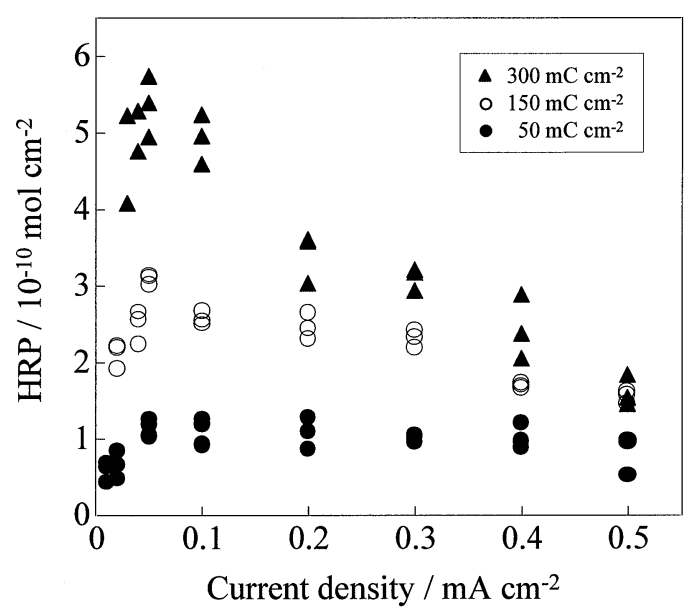

Fig. 3 Amount of HRP immobilized in HRP/Py-PS electrodes as a function of the current density during electropolymerization.

achieved at a current density of around $0.05-0.1 \mathrm{~mA} \mathrm{~cm}{ }^{-2}$.

With an increase in the deposition current density beyond this optimal value $\left(0.1-0.5 \mathrm{~mA} \mathrm{~cm}{ }^{-2}\right)$, the amount of entrapped enzyme decreased, as can be seen more noticeably for thicker films $\left(300 \mathrm{mC} \mathrm{cm}^{-2}\right)$. This may result from a better arrangement of the enzyme molecules in an electropolymerized film grown with a slower rate. As described in a previous study, ${ }^{19} \mathrm{HRP}$ is positively charged at the usual $\mathrm{pH}$ of the growth solution, and hence could be incorporated into the Py-PS copolymer via electrostatic attractions with the sulfonate groups of the polymer during electropolymerization. Presumably, a film growing with a slower rate will provide sufficient time so that the incorporation of enzyme through electrostatic attraction between enzyme and negatively-charged Py-PS copolymer is more efficient.

However, when the film growth rate was too slow (below 0.05 $\mathrm{mA} \mathrm{cm}-2$ ), the amount of entrapped enzyme tended to decrease. This aspect could be rationalized by invoking the mechanisms for the electrochemical polymerization of pyrrole on an electrode surface. The process involves a number of steps, including oxidation of the monomer to a radical cation (initiation), dimerization of the radical cation with a loss of two protons, and further oxidation and coupling reactions leading to oligomers (propagation), and finally precipitation of the polycationic polymer on the electrode. The deposition of oligomers on the electrode surface occurs only when their chain length has exceeded a specific solubility limit. When the polymerization rate is too slow, the probability of oligomer dissolution into the bulk solution increases before deposition on the electrode surface. Such a process would be favored for the highly water-soluble PS. A study on the growth behavior for electropolymerization of pyrrole and PS via electrochemical quartz crystal microgravimetry $(\mathrm{EQCM})^{24}$ showed that in the case of pyrrole, the initiation rate is smaller than the propagation rate, suggesting that the reactive monomers $\left(\mathrm{Py}^{+}\right)$ are instantaneously generated at the initial stage, and then the oligomer with a chain length larger than the critical value will deposit and become the main reactive centers $\left(\mathrm{Py}_{n}^{+}\right)$for the polymerization, and only few soluble oligomers are produced again. In the electropolymerization of PS, on the other hand, the initiation rate is comparable to or larger than the propagation rate, suggesting that reactive monomers are progressively generated. The current efficiency for the electropolymerization of PS is smaller because some soluble oligomers are dissolved 


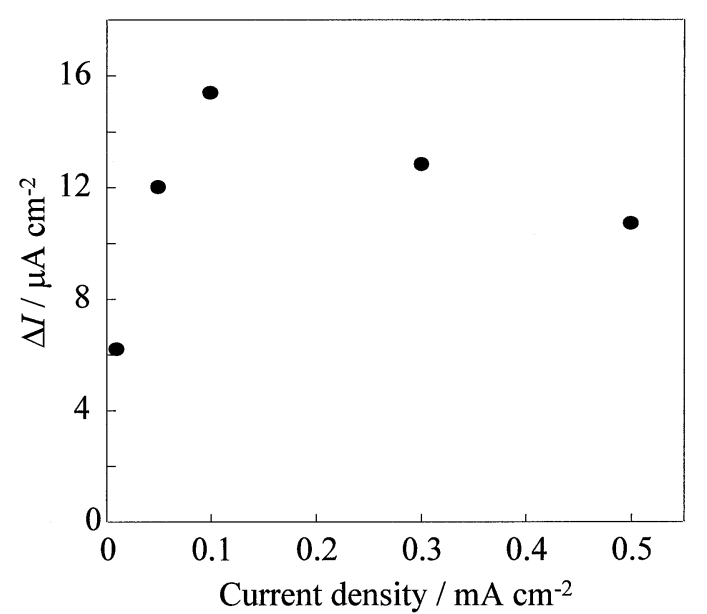

Fig. 4 Cathodic current response to $10^{-4} \mathrm{M} \mathrm{H}_{2} \mathrm{O}_{2}$ as a function of the current density during electropolymerization.

in the bulk solution during electropolymerization.

In view of this, when the electropolymerization proceeds with a too-slow rate, the Py-PS copolyer films with a lower PS content might be obtained. Since the incorporation of enzyme may be induced by electrostatic interactions, at least to a certain extent, between the enzyme and the copolymer matrix, this will suppress the enzyme incorporation into the growing polymer, leading to an observed decrease in the quantity of the enzyme immobilized at the current density below $0.05 \mathrm{~mA} \mathrm{~cm}^{-2}$.

The effect of the deposition current density on the sensor response was examined with a constant electropolymerization charge of $50 \mathrm{mC} \mathrm{cm}^{-2}$. The applied current density was varied between $0.01-0.5 \mathrm{~mA} \mathrm{~cm}{ }^{-2}$, and the sensor response was measured for a $10^{-4} \mathrm{M} \mathrm{H}_{2} \mathrm{O}_{2}$ solution. The response-deposition current density curve (Fig. 4) appears to be a counterpart of the entrapped enzyme-deposition current density curve (Fig. 3). This indicates that the cathodic current response is proportional to the amount of immobilized enzyme under these experimental conditions. A similar effect of the deposition current density was observed with an electropolymerization charge of $5 \mathrm{mC}$ $\mathrm{cm}^{-2}$, where the sensor response was smaller than that for 50 $\mathrm{mC} \mathrm{cm}^{-2}$, probably because it was controlled by the enzymatic reaction. The influence of the deposition current density $(0.1$, 0.2 and $0.5 \mathrm{~mA} \mathrm{~cm}^{-2}$ ) was also investigated with thicker films prepared from a total charge of $500 \mathrm{mC} \mathrm{cm}^{-2}$. In this case, the magnitude of the responses was between those at $5 \mathrm{mC} \mathrm{cm}^{-2}$ and $50 \mathrm{mC} \mathrm{cm}^{-2}$, with practically no dependence on the current density. This may be because the cathodic current response is controlled here not by the amount of immobilized enzyme, but by mass transfer.

It should be noted that the current density during electropolymerization is one of the critical parameters in determining such properties as the conductivity and morphology of the resulting polymer films. To predict the sensor response, these factors have to taken into account along with the amount of immobilized enzyme.

\section{Effect of the growth solution $p H$}

The mechanism by which the enzyme is incorporated into the growing polymer film is still unclear. One explanation states that a negatively-charged enzyme, especially glucose oxidase with an isoelectric point of 4.2, can serve as a counter-anion for the polycationic polymer chain., ${ }^{1,6,25}$ Another postulates simply that an enzyme can be entrapped just because it is present next

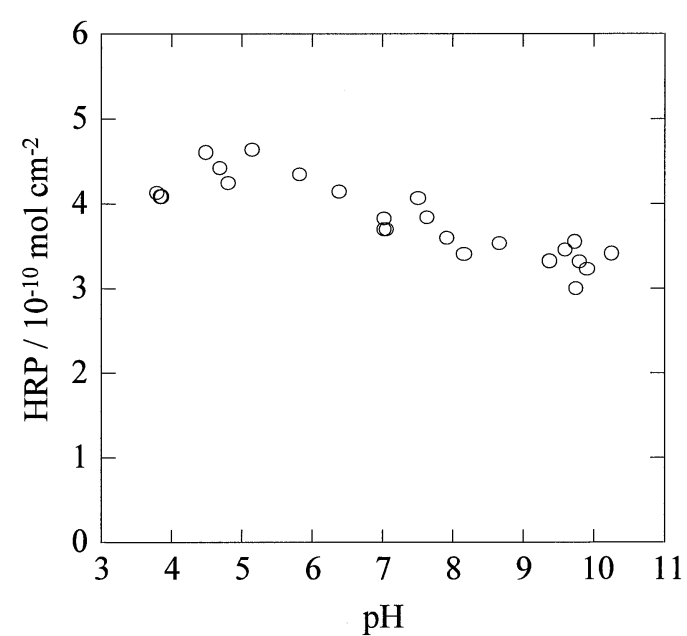

Fig. 5 Amount of HRP immobilized in HRP/Py-PS electrodes as a function of the electropolymerization solution $\mathrm{pH}$.

to the electrode surface. ${ }^{26,27}$ Additionally, it has been proposed that since polypyrrole is deposited as a polycation, electrostatic interactions between the polymer and the enzyme play an important role in enzyme incorporation. ${ }^{28}$

In a previous study we showed that the response of the HRP/Py-PS electrode decreases remarkably when prepared from an alkaline electropolymerization solution. ${ }^{19}$ HRP has an isoelectric point (pI) of 7.2, and is therefore negatively charged at a $\mathrm{pH}$ above this. Raising the $\mathrm{pH}$ would lead to an electrostatic repulsion between enzyme and polyanionic Py-PS copolymer film, and consequently the ability to entrap enzyme into the films would be reduced. To verify this, the quantity of enzyme actually incorporated into the Py-PS copolymer film at each $\mathrm{pH}$ of the growth solution must be known.

In view of this, the amount of HRP incorporated into the Py-PS copolymer films prepared in growth solutions of $\mathrm{pH} 4$ 10 was determined. $\mathrm{HCl}$ and $\mathrm{NaOH}$ were used to adjust the $\mathrm{pH}$ of the enzyme-containing monomer solution. The result is depicted in Fig. 5. It should be noted that the electropolymerization of pyrrole releases protons, which acidify the solution close to the electrode, i.e. the solution $\mathrm{pH}$ becomes lower than the initial $\mathrm{pH}$ when an unbuffered electrolyte is employed, as in this study. ${ }^{29}$ Hence, the initial $\mathrm{pH}$ given in Fig. 5 was shifted slightly toward lower values.

The films were grown with a total charge of $500 \mathrm{mC} \mathrm{cm}^{-2}$, a current density of $0.3 \mathrm{~mA} \mathrm{~cm}{ }^{-2}$, and the HRP concentration of $0.6 \mathrm{~g} \mathrm{~L}^{-1}$ in the growth solution. As can be seen in Fig. 5, the enzyme loading into the copolymer film decreases, albeit not so much, with raising the $\mathrm{pH}$ of the monomer solution. Raising the $\mathrm{pH}$ will lead to an electrostatic repulsion between enzyme and the polyanionic Py-PS copolymer film, and thus the amount of enzyme incorporated into the films decreased. The decrease in the amount of entrapped enzyme was probably one of the origins for the smaller sensor response at higher $\mathrm{pH}$ of preparation. ${ }^{19}$

However, the $\mathrm{pH}$ dependence of the sensor response ${ }^{19}$ was significantly steeper than that of the enzyme loading shown in Fig. 5. Several factors could be envisaged as origins for this discrepancy. It has been reported that the electrical conductivity, which should favor the sensor output, of asprepared polypyrrole films decreased with raising the electropolymerization solution $\mathrm{pH}$ from $c a .5$ to $8 .^{30,31}$ This may be related to the irreversible over-oxidation of polypyrrole in 
alkaline solutions, as reported by $\mathrm{Li}$ and Qian. ${ }^{32}$ Another possibility is the effect of the $\mathrm{pH}$ on the film morphology; it was suggested that the "compactness", which may suppress substrate diffusion, of the polypyrrole film was higher when formed in alkaline solutions. ${ }^{25,29}$

\section{Acknowledgements}

We are grateful to Dr. T. Tatsuma for valuable discussions.

\section{References}

1. N. C. Foulds and C. R. Lowe, J. Chem. Soc., Faraday Trans. 1, 1986, 82, 1259.

2. M. Umana and J. Waller, Anal. Chem., 1986, 58, 2979.

3. C. Iwakura, Y. Kajiya, and H. Yoneyama, J. Chem. Soc., Chem. Commun., 1988, 1019.

4. S. Yabuki, H. Shinohara, and M. Aizawa, J. Chem. Soc., Chem. Commun., 1989, 945.

5. D. Belanger, J. Nadreau, and G. Fortier, J. Electroanal Chem., 1989, 274, 143.

6. G. Fortier, E. Brassard, and D. Bélanger, Biosens. Bioelectron., 1990, 5, 473.

7. Y. Kajiya, H. Sugai, C. Iwakura, and H. Yoneyama, Anal. Chem., 1991, 63, 49.

8. U. Wollenberger, V. Bogdanovskaya, S. Bobrin, F. Scheller, and M. Tarasevich, Anal. Lett., 1990, 23, 1795

9. T. Tatsuma, M. Gondaira, and T. Watanabe, Anal. Chem., 1992, 64, 1183

10. G. E. De Benedetto, F. Palmisano, and P. G. Zambonin, Biosens. Bioelectron., 1996, 11, 1001.

11. S. S. Razola, B. L. Ruiz, N. M. Diez, H. B. Mark, and J.-M. Kauffmann, Biosens. Bioelectron., 2002, 17, 921.

12. P. N. Bartlett and R. G. Whitaker, J. Electroanal. Chem.,
1987, 224, 37.

13. N. C. Foulds and C. R. Lowe, Anal. Chem., 1988, 60, 2473.

14. P. N. Bartlett, Z. Ali, and V. Eastwick-Field, J. Chem. Soc., Faraday Trans., 1992, 88, 2677.

15. I. Willner and A. Riklin, Anal. Chem., 1994, 66, 1535.

16. J. J. Gooding, M. Situmorang, P. Erokhin, and D. B. Hibbert, Anal. Commun., 1999, 36, 225.

17. S. Thanachasai, H. Furukawa, S. Yoshida, and T. Watanabe, Chem. Lett., 2003, 32, 176.

18. M. M. Bradford, Anal. Biochem., 1976, 72, 248.

19. S. Thanachasai, S. Rokutanzono, S. Yoshida, and T. Watanabe, Anal. Sci., 2002, 18, 773 .

20. E. E. Havinga, W. ten Hoeve, E. W. Meijer, and H. Wynberg, Chem. Mater., 1989, 1, 650 .

21. H. B. Dunford and J. S. Stillman, Coord. Chem. Rev., 1976 , 19,187

22. S. Holdcroft and B. L. Funt, J. Electroanal. Chem., 1988 , 240,89 .

23. P. Gros, T. Gibson, A. Bergel, and M. Comtat, J. Electroanal. Chem., 1997, 437, 125.

24. B. J. Hwang, D. T. Shieh, W. C. Chieh, D.-J. Liaw, and L.-J. Li, Thin Solid Films, 1997, 301, 175.

25. N. F. Almeida, E. J. Beckman, and M. M. Ataai, Biotechnol. Bioeng., 1993, 42, 1037.

26. W. Schuhmann, Mikrochim. Acta, 1995, 121, 1 .

27. W. Schuhmann, C. Kranz, H. Wohlschläger, and J. Strohmeier, Biosens. Bioelectron., 1997, 12, 1157.

28. P. N. Bartlett and J. M. Cooper, J. Electroanal. Chem., 1993, 362, 1

29. S. Asavapiriyanont, G. K. Chandler, G. A. Gunawardena, and D. Pletcher, J. Electroanal. Chem., 1984, 177, 229.

30. W. Wernet, M. Monkenbusch, and G. Wegner, Mol. Cryst. Liq. Cryst., 1985, 118, 193.

31. Y. Li and J. Ouyang, Synth. Met., 2000, 113, 23.

32. Y. Li and R. Qian, Electrochim. Acta, 2000, 45, 1727. 